\title{
As Vozes de Professores-Pesquisadores do Campo da Educação Ambiental sobre a Base Nacional Comum Curricular (BNCC): Educação Infantil ao Ensino Fundamental
}

\section{The Voices of Teachers-Researchers in the Field of Environmental Education on the National Common Curricular Base (BNCC): Early Childhood Education to Primary School}

\author{
Silvana do Nascimento Silva' \\ Carlos Frederico Bernardo Loureiro² \\ 'Universidade Estadual do Sudoeste da Bahia (UESB), Departamento de Biologia, Jequié, BA, Brasil.
Autora correspondente: silvananascimento@uesb.edu.br
${ }^{2}$ Universidade Federal do Rio de Janeiro (UFRJ), Faculdade de Educação, Rio de Janeiro, RJ, Brasil.
}

Resumo: A pesquisa qualitativa que balizou a produção desse artigo objetivou categorizar as vozes de professores-pesquisadores do campo da educação ambiental sobre a Base Nacional Comum Curricular (BNCC), por meio de entrevista semiestruturada e da análise textual discursiva das quais emergiram as seguintes categorias: interação, espaço e abordagens da BNCC, concepções sobre BNCC e educação ambiental na BNCC. As vozes dos entrevistados se coadunam com o que afirma a literatura aqui apresentada sobre as críticas à BNCC, no que tange a currículo mínimo, superficialidade e redução de conteúdos críticos, precarização e privatização da educação, formação voltada para o ditame do mercado. No âmbito da EA, a instrumentalização do tema e a ausência de abordagens críticas também foram salientadas, o que reforça o posicionamento de que esta é utilizada como elemento de reforço de uma formação voltada para os ideais neoliberais e meritocráticos.

Palavras-chave: Educação ambiental; BNCC; Currículo; Políticas públicas.

\begin{abstract}
The qualitative research that led to the production of this article aimed to categorize the voices of teachers-researchers in the field of environmental education on the BNCC, through a semi-structured interview and discursive textual analysis of which emerged the following categories: interaction, space and approaches of the BNCC, conceptions about the BNCC, and environmental education in the BNCC. The interviewees' voices are in line with what the literature says about the criticisms on the BNCC regarding minimum curriculum, superficiality and reduction of critical content, education precariousness and privatization, and market-oriented training. In the context of environmental education, the instrumentalization of the issue and the absence of critical approaches were also emphasized, reinforcing the position that environmental education is used as an element reinforcing a formation focused on neoliberal and meritocratic ideals.
\end{abstract}

Keywords: Environmental education; BNCC; Curriculum; Public policies. 


\section{Introdução}

Compreende-se por Base Nacional Comum Curricular (BNCC) o documento oficial que define direitos e objetivos de aprendizagem e desenvolvimento que orientarão a elaboração dos currículos nacionais. Assim, o documento preconiza objetivos que devem percorrer as etapas de parte da Educação Básica (BRASIL, 2016).

A BNCC se materializou em 2017, com a produção da versão final desse documento fundamentada nas orientações apresentadas na Constituição Federal, Leis de Diretrizes e Bases, Diretrizes Curriculares Nacionais Gerais da Educação Básica e Plano Nacional de Educação. Ainda se tornou meta do Ministério da Educação (MEC) atrelá-la às demais políticas públicas, como a Política Nacional de Formação de Professores, a Política Nacional de Materiais e Tecnologias Educacionais, a Política Nacional de Infraestrutura Escolar e a Política Nacional de Avaliação da Educação Básica (BRASIL, 2016; MACEDO, 2016).

A elaboração da primeira versão da BNCC foi aberta para consulta pública entre setembro de 2015 e março de 2016. Com base nas contribuições recebidas de indivíduos, organizações e redes, pesquisadores da Universidade de Brasília (UnB) e da Pontifícia Universidade Católica do Rio de Janeiro (PUC-RJ), a segunda versão foi elaborada e publicada em 2016. Essa nova versão passou por debates institucionais via apresentação de seminários sob a responsabilidade das Secretarias Estaduais de Educação, em parceria com o Conselho Nacional de Secretários da Educação (CONSED) e a União Nacional dos Dirigentes Municipais de Educação (UNDIME), em todas as unidades da Federação. O público-alvo dos seminários foram professores, gestores, especialistas e entidades de educação. Assim, também eram coletadas contribuições para elaboração da terceira versão da BNCC (BRASIL, 2017).

Em meio a todo o processo de elaboração da BNCC embates foram travados pelos próprios Conselheiros do Conselho Pleno e a Comissão Nacional de Educação (CNE) sobre os limites na avaliação das contribuições das audiências públicas em que muitas não foram devidamente discutidas em razão da pressa em aprovar a versão final (AGUIAR, 2018).

A Associação Nacional de Pós-Graduação e Pesquisa em Educação (ANPED), no colóquio realizado em abril de 2016, no Rio de Janeiro, se colocou em posição contrária à metodologia adotada pelo MEC, pois, para representantes de várias áreas de conhecimento, não houve um amplo debate sobre o tema com os atores sociais do contexto escolar. Eles argumentam que toda essa tarefa ficou concentrada no rol de especialistas selecionados pelo próprio MEC (VEIGA, 2016), o que caracterizou uma elaboração vertical e centralizadora (AGUIAR, 2018).

Aguiar (2018, p. 19) destaca que a garantia de direitos à aprendizagem e ao desenvolvimento dos estudantes vão além de uma base nacional comum, perpassando por garantir o que preconiza o Plano Nacional de Educação (PNE) em relação à “[...] universalização da Educação Básica obrigatória, educação em tempo integral, [...] a valorização dos profissionais da educação".

Macedo (2016, p. 54) reforça ainda mais as críticas sobre a produção da BNCC no que diz respeito ao conflito que existe em, de um lado, listar um conjunto de conhecimentos como essenciais, e do outro, definir o que não pode ser ensinado. Na visão da autora, a "[...] descrição dos conteúdos é suplementada por uma listagem dos padrões de aprendizagem a serem atingidos [...]". 


\section{A Educação Ambiental (EA) como Campo e o Silenciamento na BNCC}

O espaço reservado à EA na BNCC vem sendo questionado desde as versões anteriores nos trabalhos de Andrade e Piccinini (2017), Santinelo, Royer e Zanatta (2016) e Wutzki e Tonso (2017). Para estes, as versões da BNCC não abordam a EA de forma crítica e com profundidade sobre as abordagens socioambientais. O que leva a um total silenciamento do que é discutido e produzido pelo campo no Brasil.

As diferentes versões desconsideram que a EA se integra ao campo socioambiental no qual ocorrem produção e circulação de conhecimentos. Nesse campo, que se encontra em constante construção, atuam diversas ideologias, conflitos e interesses que são materializados por atores sociais diversos (SILVA; EL-HANI, 2014).

Nesse campo também ocorre a produção de conhecimento e se firma a necessidade pela interação de saberes. Estes são produzidos por práticas sociais que abarcam comportamentos, atitudes e valores que demarcam as formas de interação e concepção sobre o ambiente, em sociedades compostas por classes sociais (LOUREIRO, 2002).

Em tais saberes, convivem as concepções e práticas sobre a EA, ambiente, sociedade e natureza, que destacam a forma como diferentes grupos sociais percebem e atuam no ambiente, configurando tendências político-pedagógicas que se identificam pelas diferentes denominações que lhes são atribuídas. Assim, entre outras classificações possíveis, encontramos a Pragmática, pautada na metodologia de resolução de problemas locais, que se fundamenta na mudança comportamental. A Conservacionista, em que a prática é estabelecida a partir da sensibilização para o culto à natureza, pautado na preservação e na conscientização ecológica, e a Crítica, que aborda o processo da reprodução social, em que a tríade ser humano-sociedade-natureza é investigada a partir das relações socioculturais e de classes (LAYRARGUES; LIMA 2014).

\section{A BNCC como Política Pública Educacional no Âmbito Curricular a Favor da Parceria Público-Privado}

Segundo Souza (2006), o conceito de políticas públicas é polissêmico. Aqui, o conceito é concebido como um conjunto de ações organizadas pelo Governo, estabelecendo parcerias com grupos (empresas, organizações, corporações, instituições, movimentos sociais e a sociedade civil de forma geral) com o objetivo de pôr em prática ações que visam a realizar e sedimentar os interesses - econômicos, sociais, políticos, por exemplo - de setores específicos da sociedade

Venco e Carneiro (2018, p. 7) destacam que por meio da política pública da BNCC "o Brasil opta, seguindo sua tradição, por uma educação submissa aos países centrais e permanece se inscrevendo subalternamente na divisão internacional do trabalho". Isso fica bem claro quando associamos a Emenda Constitucional (EC) 95, que acarreta a desobrigação do Estado de investir no campo da Educação, por exemplo, pautando-se pela concepção política do Estado mínimo.

Nessa concepção o Estado trata direitos sociais como serviços, e setores privados se movem para o interior dos espaços educacionais públicos, legitimando, via Estado, políticas privatistas. Na parceria ente público-privado é que se enquadra a BNCC, com o objetivo de promover o direito de aprendizagem e desenvolvimento dos estudantes da Educação 
Infantil ao Ensino Fundamental, mas que não passa de um instrumento em prol do favorecimento dos interesses do mercado (AGUIAR, 2018), garantido principalmente pelas conexões com setor empresarial que se infiltram nos setores da Educação.

O Estado, com caráter educador, regulador e avaliador, passa a promover contrarreformas (por exemplo: reforma do ensino médio, BNCC), de modo que, segundo Leher (2003, p. 35), "para escapar das 'armadilhas da democracia', os governos afinados com esse pensamento promovem uma radical reforma do Estado, de forma que o interesse privado suplante o público". Assim, "[c]ertas obrigações do Estado com o ensino fundamental, em especial para as populações 'pobres', são aceitáveis na ótica neoliberal" (LEHER, 2003, p. 45).

O discurso dessa parceria, partindo desse pressuposto tende a legitimar que o público é uma extensão do privado, e "[...] a redução da esfera pública poderia ser compensada pelo fortalecimento da esfera privada." (LEHER, 2005, p. 132). Nesse sentido são legitimadas as parceiras com Itaú social, Instituto Ayrton Senna, Todos pela Educação, Fundação Lemann.

\title{
Delineamento Metodológico
}

A abordagem qualitativa balizou o caminhar metodológico por primar pela coleta de informações de forma descritiva, apontando os significados das concepções das falas dos entrevistados. Nesse caminho a pesquisa se caracterizou por apresentar as seguintes características, seguindo Bogdan e Biklen (1994, p. 48):

\begin{abstract}
Os dados recolhidos são em forma de palavras ou imagens e não de números. Os resultados escritos da investigação contêm citações feitas com base nos dados para ilustrar e substanciar a apresentação. Os dados incluem transcrições de entrevistas [...] contendo narrativas e outros dados [...] Tentam analisar os dados em toda sua riqueza, respeitando, tanto quanto o possível, a forma em que estes foram registrados ou transcritos.
\end{abstract}

A entrevista foi semiestruturada com questões subjetivas que versavam sobre o perfil dos entrevistados (formação acadêmica e atuação profissional), nível de interação, espaços de interação, concepções sobre a BNCC e abordagem da educação ambiental em tal documento.

O perfil dos entrevistados é composto por oito profissionais da área de Educação Ambiental apresentando formação em Ecologia, Ciências Biológicas, Geografia, Filosofia e Ciências Sociais, a maioria com mestrado e doutorado em Educação (Quadro 1). A maioria também atua na rede pública de ensino do Rio de Janeiro, e outros em Instituição de pesquisa e rede privada de ensino. O tempo de serviço varia entre 6 a 35 anos.

Por uma questão de ética, os entrevistados leram eassinaram o termo de consentimento livre e esclarecido sobre o teor da pesquisa, e conforme a garantia de anonimato, os entrevistados receberam nomes fictícios conforme apresentados no quadro 1. 
Quadro 1 - Perfil dos sujeitos pesquisados

\begin{tabular}{|c|c|c|c|c|c|c|}
\hline Entrevistados & Gênero & Graduação & Mestrado & Doutorado & Área de atuação & $\begin{array}{l}\text { Tempo de } \\
\text { atuação }\end{array}$ \\
\hline Democracia & Feminino & $\begin{array}{l}\text { Bacharelado } \\
\text { em ecologia e } \\
\text { licenciatura em } \\
\text { ciências biológicas }\end{array}$ & Educação & Educação & $\begin{array}{l}\text { Educação ambiental; } \\
\text { Ciências e biologia; } \\
\text { Formação docente . }\end{array}$ & 25 anos \\
\hline Educação & Feminino & $\begin{array}{l}\text { Licenciatura em } \\
\text { ciências biológicas }\end{array}$ & Educação & Ecologia social & $\begin{array}{l}\text { Educação ambiental; } \\
\text { Ensino de ciências } \\
\text { (anos iniciais do ensino } \\
\text { fundamental). }\end{array}$ & 36 anos \\
\hline Coragem & Masculino & $\begin{array}{l}\text { Licenciatura e } \\
\text { bacharelado em } \\
\text { ciências biológicas }\end{array}$ & Educação & - & $\begin{array}{l}\text { Educação ambienta; } \\
\text { Biologia. }\end{array}$ & 6 anos \\
\hline Igualdade & Masculino & $\begin{array}{l}\text { Licenciatura em } \\
\text { geografia }\end{array}$ & Ciências & Educação & $\begin{array}{l}\text { Educação ambiental; } \\
\text { Geografia. }\end{array}$ & 22 anos \\
\hline Liberdade & Feminino & Ciências biológicas & $\begin{array}{l}\text { Geoquímica } \\
\text { ambiental }\end{array}$ & $\begin{array}{l}\text { Biotecnologia } \\
\text { vegetal }\end{array}$ & $\begin{array}{l}\text { Biodiversidade vegetal; } \\
\text { Organografia e } \\
\text { taxinomia vegetal; } \\
\text { Meio ambiente e } \\
\text { sociedade. }\end{array}$ & 23 anos \\
\hline Luta & Feminino & $\begin{array}{l}\text { Licenciatura em filo- } \\
\text { sofia }\end{array}$ & Educação & Educação & $\begin{array}{l}\text { Educação, artes, } \\
\text { poema, cultura; } \\
\text { Educação ambiental. }\end{array}$ & 11 anos \\
\hline Resistência & Feminino & $\begin{array}{l}\text { Ecologia e } \\
\text { licenciatura plena } \\
\text { em ciências } \\
\text { biológicas }\end{array}$ & Educação & Educação & $\begin{array}{l}\text { Educação ambiental; } \\
\text { Direitos humanos; } \\
\text { Palinotaxonomia. }\end{array}$ & 12 anos \\
\hline Revolução & Feminino & Ciências sociais & Educação & $\begin{array}{l}\text { Psicossocio- } \\
\text { logia de co- } \\
\text { munidades e } \\
\text { Ecologia social }\end{array}$ & Educação ambiental & 35 anos \\
\hline
\end{tabular}

Fonte: elaborado pelos autores.

A análise das entrevistas foi estruturada com base na análise textual discursiva (ATD) proposta por Moraes e Galiazzi (2011), foram transcritas formando textos distintos para contemplar as três etapas do mecanismo da ATD, descritas a seguir: a desconstrução - etapa em que ocorre a desagregação dos textos; a unitarização - ou a formação de relações entre os elementos que compõem o texto e, finalmente, a categorização - a elaboração de categorias, tomando por base os dados emergentes no processo analítico.

Os processos de desconstrução e unitarização do texto que compõem as entrevistas transcritas foram pautados na leitura minuciosa. O processo de unitarização do texto foi realizado a partir das semelhanças e diferenças que compunham as respostas das questões das entrevistas.

As categorias e subcategorias emergentes do processo de desconstrução e unitarização se encontram destacadas no quadro 2.

Quadro 2 - Categorias e subcategorias emergentes da ATD das entrevistas

\begin{tabular}{|l|l|}
\hline \multicolumn{1}{|c|}{ Categorias } & \multicolumn{1}{c|}{ Subcategorias } \\
\hline Interação, espaço e abordagem da BNCC & \\
\hline Concepções sobre a BNCC & $\begin{array}{l}\text { Currículo mínimo / Política pública / Precarização da educação pública / Processo } \\
\text { de elaboração }\end{array}$ \\
\hline Educação ambiental na BNCC & $\begin{array}{l}\text { Abordagem superficial / Abordagem técnica / Abordagem conservacionista e prag- } \\
\text { mática }\end{array}$ \\
\hline
\end{tabular}

Fonte: elaborado pelos autores. 
As descrições e interpretações das categorias formam os metatextos que, segundo Moraes e Galiazzi (2011, p. 32), definem-se como "[...] constituídos de descrição e interpretação, representando o conjunto", isto é, um metatexto já se configura como "um modo de teorização sobre os fenômenos investigados".

\section{Discussão dos Resultados}

Os resultados são apresentados de acordo com as três categorias que emergiram da ATD das entrevistas semiestruturadas, são elas: Interação, espaços e abordagem da BNCC; Concepções sobre BNCC e Educação Ambiental na BNCC.

\section{Interação, Espaços e Abordagem da BNCC}

Em relação à interação com a BNCC, três entrevistados alegaram não ter tido a oportunidade de se debruçar sobre o conteúdo do documento, e os cinco restantes relataram ter tido interação não aprofundada, mas direcionada para os conteúdos de ciências e/ou meio ambiente.

Percebe-se que a interação se estabelece no nível da leitura e estudo específico da área de atuação e/ou formação. O que acarreta no recorte do que se deseja conhecer do documento.

Segundo as falas dos entrevistados o contato com a BNCC se materializou nos seguintes espaços: escola, universidade (grupo de pesquisa, projeto de extensão e seminários), site da BNCC e mídia (Quadro 3).

O site da BNCC também foi destacado relacionado a consulta pública amplamente divulgada principalmente pela mídia.

Chamamos a atenção para o espaço mídia no tocante as parcerias que são estabelecidas, conforme destacam a seguir Stankevecz e Castillo (2018, p. 43):

\footnotetext{
Houve, na discussão do currículo nacional, um peso preponderante das ONGs, fundações e instituições vinculadas a interesses empresariais. Estas organizações e fundações, que vêm ganhando espaço no âmbito educacional nacional, foram autoras de um quarto das matérias publicadas, sendo o mais relevante autor após os próprios jornalistas. Além disso, foram o ator mais frequentemente citado nas matérias do jornal, sejam estas editoriais, colunas, etc.
}

As autoras ainda destacam sobre o teor vinculado no jornal (mídia) investigado que endossava a BNCC "[...] mediante a valorização dos currículos nacionais implementados em outros países, assim como tenderam a veicular preferencialmente as visões das fundações e organizações empresariais" (STANKEVECZ; CASTILLO, 2018, p. 43).

Em relação às respostas dos entrevistados, as abordagens realizadas em tais espaços alternam entre os seguintes tipos: sentido de privatização da educação, redução (enxugamento) de conteúdo, precarização da formação docente, ensino e educação, pontos positivos e negativos da estrutura curricular de ciências para os anos iniciais, retrocessos no tratamento das questões sociais, conceito e uso técnico da natureza, análise do tema meio ambiente, normatização do ensino, obrigatoriedade dos conteúdos selecionados, visão mercadológica da educação, consequências. 
para o ensino e posicionamento docente quanto às orientações da base (Quadro 3).

Tais abordagens indicadas pelos entrevistados sobre a BNCC, se aproximam dos resultados obtidos por Rocha e Pereira (2016, p. 224) ao mapear as produções científicas divulgadas entre 2010-2013 no âmbito da BNCC, que destacaram as seguintes ideias e concepções: "[...] práticas de controle e tentativa de homogeneidade; política neoliberal vinculada à politicas de avaliação; instrumento de regulação; reprodução da experiência internacional e documento desnecessário devido a existência de outros documentos competentes".

Abordagens sobre o sentido de privatização da educação ganharam mais notoriedade no espaço acadêmico quando da promulgação da Emenda Constitucional 95, que passou a limitar por 20 anos os investimentos do governo federal nos campos da educação, saúde, cultura, trabalho... Nessa redução da participação do Estado ou sua completa ausência em investimento nesses campos, Venco e Carneiro (2018) compreendem que essa prática permite a ação do setor privado no serviço público, o que consequentemente legaliza a privatização. Além disso, no campo da Educação, permite aprofundar o projeto de sua precarização que abrange o chão da escola e a formação docente.

A normatização do ensino não foge aos temas de discussões sobre a BNCC, pois se alinha a outros como obrigatoriedade de conteúdos e redução ou esvaziamento das questões sociais em tal documento. A BNCC se caracteriza por se estruturar como um currículo mínimo baseado em competências e habilidades (LOPES, 2018) que endossam a ligação mercadológica em perpetuar a educação aos ditames do modelo capitalista (VENCO; CARNEIRO, 2018) e forja a formação dos estudantes ao mercado de trabalho (MAZZEU, 2007). Reforçando o ensino aligeirado alinhado a visão técnica com o discurso da suposta 'empregabilidade'.

Em relação à abordagem sobre meio ambiente ou temas correlatos em $\mathrm{EA}$, as vozes dos entrevistados se coadunam com a literatura (ANDRADE; PICCININI, 2017; SANTINELO; ROYER; ZANATA, 2016; WUTZKI; TONSO, 2017), sobre a redução, silenciamento ou completa ausência de abordagens críticas do campo ambiental no decorrer das versões da BNCC, forjando currículos e projetos políticos pedagógicos desconectados aos debates socioambientais e reduzindo a EA a dimensão de temas.

Quadro 3 - Interação, espaço e abordagens da BNCC pelos entrevistados

\begin{tabular}{|l|c|l|l|}
\hline Entrevistados & $\begin{array}{c}\text { Interação } \\
\text { com a BNCC }\end{array}$ & \multicolumn{1}{|c|}{ Espaço } & \multicolumn{1}{c|}{ Abordagens } \\
\hline Democracia & Sim & $\begin{array}{l}\text { Já tive contato com um trabalho de } \\
\text { uma colega da universidade que } \\
\text { pesquisou a Educação ambiental na } \\
\text { BNCC }\end{array}$ & $\begin{array}{l}\text { sentido de privatização da educação } \\
- \text { enxugamento de conteúdo } \\
\text { precarização da formação docente } \\
\text { precarização do ensino } \\
\text { precarização da Educação }\end{array}$ \\
\hline Educação & Sim & $\begin{array}{l}\text { Escola onde atua: via seminários } \\
\text { realizados pelos departamentos }\end{array}$ & $\begin{array}{l}\text { - pontos positivos e negativos da } \\
\text { estrutura curricular de ciências para os } \\
\text { anos iniciais } \\
\text { retrocessos das questões sociais } \\
\text { conceito e uso técnico da natureza }\end{array}$ \\
\hline Coragem & Sim & $\begin{array}{l}\text { Projetos de extensão, mídia, } \\
\text { eventos, site da BNCC e via amigos } \\
\text { acadêmicos }\end{array}$ & $\begin{array}{l}\text { - normartização do ensino } \\
- \text { obrigatoriedade dos conteúdos } \\
\text { selecionados }\end{array}$ \\
\hline Igualdade & Não & $\begin{array}{l}\text { Depoimentos de colegas alegando ser um } \\
\text { documento muito simplista, que não leva } \\
\text { em consideração as diferenças regionais. } \\
\text { orientado para uma visão um pouco mais } \\
\text { mercadológica da Educação. }\end{array}$ \\
\hline
\end{tabular}




\begin{tabular}{|c|c|c|c|}
\hline Entrevistados & $\begin{array}{l}\text { Interação } \\
\text { com a BNCC }\end{array}$ & Espaço & Abordagens \\
\hline Liberdade & Não & Não especificado & - \\
\hline Luta & Sim & $\begin{array}{l}\text { Evento (Congresso); } \\
\text { Consulta pública }\end{array}$ & - análise sobre o tema meio ambiente \\
\hline Resistência & Sim & Colégio em que atua & $\begin{array}{l}\text { - saber quais serão as consequências para } \\
\text { o ensino } \\
\text { - como iremos nos relacionar com essa } \\
\text { nova orientação }\end{array}$ \\
\hline Revolução & Não & $\begin{array}{l}\text { Propaganda na TV; } \\
\text { Grupo de pesquisa. }\end{array}$ & Não respondeu \\
\hline
\end{tabular}

Fonte: elaborado pelos autores.

\section{Concepções sobre a BNNC}

Da categoria concepções sobre a BNCC emergiram as seguintes subcategorias: currículo mínimo, política pública, precarização da educação pública e processo de elaboração.

As concepções dos entrevistados sobre a BNCC, pautadas em termos de currículo mínimo, destacam o enxugamento e a padronização dos conteúdos, conforme apresentam as transcrições a seguir:

A BNCC é um atraso quanto à ideia de ter um currículo comum, um currículo único que vai representar o pais inteiro, e, sobretudo com essas perspectivas de enxugamento de conteúdo. [Democracia].

Eu acho que a base tá perdendo tudo que os $P C N$ trouxeram de avanço no que se refere à relação da sociedade com as áreas de conhecimento, que traz a relação do conhecimento com o cotidiano social. [Educação].

Eu não li a BNCC, mas a princípio você, vendo algumas propagandas em que o menino do nordeste e o do sudeste têm que ter a mesma base, mas que leve em consideração questões específicas e regionais. A discussão da base é antiga e procede, mas que base é essa? A partir de qual currículo tá se falando em base? [Revolução].

A fala de Revolução quando questiona sobre "que base é essa? A partir de qual currículo tá se falando em base?" se aproxima com o que a literatura destaca sobre o currículo como espaço de poder, controle, anunciações, denúncias, negociações... ao se pretender implementar uma política de educação voltada para o currículo (BRASILEIRO; VALENGA; COLARES, 2010; LOPES; MACEDO, 2002;). Nessa conjuntura, interesses vinculados a aspectos sociológicos, econômicos, políticos, religiosos... são norteadores de sua elaboração, muitas vezes legitimando o discurso hegemônico daqueles que controlam a nação, e assim primam pela formação conservadora em que há o favorecimento de conhecimentos de áreas mais técnicas que supostamente fomentaram a mobilidade de competências e habilidades requeridas pelo mercado de trabalho. Conhecimentos de áreas voltadas para a criticidade e libertação do cidadão como membro atuante da sociedade são postos em segundo plano ou totalmente negligenciados. Nessa direção caminha para o dito enxugamento de conteúdos sinalizado por Democracia. 
As concepções também abrangeram a BNCC, vista como política pública por ser uma iniciativa da base governamental em que se posta a consulta pública, votada e aprovada pelas instâncias ministeriais. Vejamos as falas transcritas dos entrevistados.

A BNCC partiu de uma iniciativa governamental que é o que Estado compreende como necessário para formar o cidadão brasileiro [...]. Ela foi formulada pensando em atender o interesse de um setor da sociedade. [Coragem].

Faz parte de um arcabouço legal que foi votado e aprovado há pouco tempo, junto com outros contextos referentes à legislação. Sei que se trata de um guia de parâmetros que serão utilizados para todos os programas no país inteiro. [lgualdade].

Eu conheço muito pouco da BNCC, por isso tenho muito cuidado ao falar porque existe um processo, e isso é uma parte importante. Um processo de construção, mas quanto a ele ter sido bem feito ou não, eu não sei, mas ele existir, eu acho que já é um ponto positivo. Eu acho que isso é uma coisa importante. Mas a minha experiência não foi muito boa. [Luta].

O processo de elaboração da BNCC foi muito excludente e por isso tenho ressalvas em relação à consulta pública. [Resistência].

Nas falas de Coragem e Igualdade, a política pública se evidencia quando os entrevistados se referem a iniciativa governamental e arcabouço legal elaborados para, de forma geral, atender à sociedade. Coragem ainda destaca que a BNCC foi formulada para "atender o interesse de um setor da sociedade". Esse setor é representado pelas parcerias com instituições privadas, que sustenta a parceria entre privado-público e redução da esfera do Estado.

Essa parceria caracteriza também abrir espaço para que políticas públicas voltadas para programas educacionais, desvinculados com as produções acadêmicas realizadas no âmbito do Brasil e favorecendo projetos internacionais que não se aplicam ao contexto da educação deste país.

No caso da BNCC, é público e notório as parcerias com empresas privadas nacionais e internacionais. Um exemplo é a MindLAB, que atua na formação de professores e produção de jogos educativos. Ela desenvolve parcerias com a Yale University, em que desenvolvem estudos experimentais. Na literatura de pesquisas científicas no campo educacional, a validade desse tipo metodologia de experimentação passou a ser criticada desde 1970 (MACEDO, 2018).

Nessa direção, grupos empresariais (privados) passam a se organizar pelos setores do governo (público), a definir e redefinir as políticas educacionais. As parcerias com o setor empresarial ou instituições privadas são as mais diversas possíveis, como as estabelecidas com o Instituto Unibanco, Instituto Ayrton Senna, Instituto Natura, Instituto Fernando Henrique Cardoso e tantos outros. Esse é um movimento que prima pela privatização da Educação Básica com forte disputa na oferta educativa, gestão educacional e currículo (ADRIÃO; PERONI, 2018).

O serviço público do setor educacional passa a ser serviço de mercado, em que "[...] o bem comum educativo para todos é substituído por bens diversos, desigualmente acessíveis". Assim, os seus consumidores passam a receber os produtos educacionais "[...] de natureza e qualidade desiguais" (BARROSO, 2005, p. 726). 
Nessa perspectiva, Venco e Carneiro (2017, p. 7) advogam que a BNCC está pautada em um projeto neoliberal e prioriza os interesses internacionais, na medida em que segue como princípio base a padronização da educação brasileira seguindo parâmetros mundiais.

Luta e Resistência destacam ressalvas sobre o processo de consulta pública da BNCC, o que também acompanha a literatura em que se destaca o caráter centralizador a cargo dos especialistas selecionados pelo MEC (VEIGA, 2016), o que caracteriza uma elaboração vertical e centralizadora (AGUIAR, 2018).

Por fim, a concepção da precarização da educação pública também foi destacada, veja a seguir.

Entendo como um retrocesso que vem na esteira das atuais perdas de direitos sociais, incluindo saúde e educação pública de qualidade. Vejo como uma ação voltada para estreitar as possibilidades de reflexão e acesso à informação por parte de estudantes de escolas públicas, aos quais basta saber 'ler e somar' para estarem preparados a participar do processo de produção capitalista como trabalhadores sem qualificação. Entendo que escolas particulares manterão o ensino de disciplinas que sofrem forte pressão por parte dos setores conservadores que desejam a reforma, para serem consideradas secundárias ou desnecessárias, como filosofia, sociologia, história, etc. [Liberdade].

É nessa perspectiva que grupos conservadores tentam sustentar a educação nas escolas como reprodutora das desigualdades sociais e pela reprodução social como violência simbólica (SAVIANI, 2018), sem que professores e estudantes possam se posicionar ou pautarem suas ações na criticidade do arcabouço de conhecimentos socializados no chão da escola. O ensino volta-se para atender a demanda do mercado na formação hipotética de força de trabalho em que, para o sujeito em formação, basta ter competências técnicas e ser ideologicamente disciplinados (FRIGOTTO, 2005).

Segundo Venco e Carneiro (2018) em relação às escolas privadas, estas não se enquadrarão nos pressupostos da BNCC, por considerar tal documento como um retrocesso no campo da alfabetização considerando os avanços dos últimos 30 anos da Educação. $O$ que se coaduna com a fala transcrita de Liberdade sobre a manutenção por parte de tais escolas das disciplinas de cunho mais crítico (Sociologia, Filosofia e História).

Nessa direção, percebe-se o caráter dual das escolas (pública e privada), em que uma escola de cultura geral para as classes dirigentes e uma escola do trabalho produtivo e alienado para os jovens das classes populares filho dos trabalhadores (FRIGOTTO, 2005, p. 249).

Essa diferenciação entre escolas pública e privada é compreendida por Saviani (2018) como um instrumento de reprodução das relações de produção do sistema capitalista que prima pela dominação e exploração. O que para o autor forja fielmente o caráter segregador e marginalizador da escola de natureza essencialmente seletiva e dual.

Saviani (2018, p. 25) elucida que nessa escola seletiva e dual determinada socialmente é impregnada de interesses opostos das classes sociais. Para o autor, a classe dominante "[...] não tem interesse na transformação histórica da escola (ela está empenhada na preservação de seu domínio, portanto, apenas acionará mecanismo de adaptação que evitem a transformação)".

A dualidade entre tais escolas é um processo histórico, e vale salientar que ao longo do tempo foram efetivadas reformas educacionais que não diminuíram esse caráter dual. 
Atualmente nos deparamos com a reforma da educação básica, em que a BNCC é o carro chefe, e é nesse sentido que concordamos com Frigotto (2005, p. 227) ao argumentar sobre a educação aligeirada presente em tais reformas, e que objetiva "[...] formar uma força de trabalho técnica e ideologicamente disciplinada" (FRIGOTTO, 2005, p. 227) sem capacidade crítica para interpelar os ditames da sociedade capitalista.

As desigualdades sociais gritantes que permeiam a sociedade capitalista passam a ser transferidas para as desigualdades educacionais. Nessa direção, a BNCC com todo seu aparato textual atualizado e com uma retórica que prima pelos direitos à aprendizagem, na verdade recai no que Frigotto (2005, p. 233) também destacou sobre as diretrizes curriculares anteriores à BNCC, "[...] centram-se em uma concepção produtivista e empresarial das competências e da competitividade".

\section{Educação Ambiental na BNNC}

Os entrevistados, ao serem indagados sobre como compreendem a abordagem da educação ambiental na BNCC, de forma geral construíram suas respostas em torno das seguintes subcategorias: abordagem superficial, abordagem técnica, abordagem conservacionista e pragmática.

Como abordagem superficial, as falas dos entrevistados destacam o aligeiramento, a generalização e o espaço limitado, conforme consta nas falas transcritas de Democracia, Igualdade e Luta.

A educação ambiental aparece de forma aligeirada, porque vem falando de forma transversal e integradora, vai acrescentando outros temas sem na verdade estar dizendo nada. Não adianta citar uma lei ou resoluções se você não está fornecendo subsídio para essa educação ambiental de fato acontecer nas escolas. [Democracia].

Já o enunciado sobre educação ambiental como tema, é simplista, superficial, generalista, porque não trata a educação ambiental com a devida profundidade que ela deveria ter, no mundo em que a gente vive com profundos impactos ambientais, todos os dias ameaçando a própria vida e a própria humanidade de uma forma geral, e sobretudo é compartimentado, não fornece uma visão holística, uma visão total. [lgualdade].

O posicionamento, a organização e a forma como são tratados temas tão essenciais e fundamentais, inclusive para questionar a educação que a gente está seguindo até hoje, que é completamente arcaica, evidenciam o descaso com questões extremamente fundamentais para poder fazer florescer uma educação do século XXI. Realmente, estão aqui colocados como se fosse o finalzinho do texto, olha sobrou essa migalhinha aqui, você coloca no potinho e vai. [Luta].

Essa superficialidade no tratamento da EA vem sendo apontada na literatura desde as primeiras versões da BNCC.

Santinelo, Royer e Zanatta (2016), que analisaram a educação ambiental no contexto preliminar da BNCC da primeira versão, constataram que, como tema, ela é abordada de forma superficial, fortalecendo a sua ênfase nas ciências naturais, o que intensifica a visão puramente ecológica.

Os autores Wutzki e Tonso (2017), que analisaram a segunda versão da BNCC, afirmam que as abordagens sobre EA na área de Ciências da Natureza ainda apresentam um hiato que 
não favorece o entendimento crítico dos conflitos socioambientais.

As pesquisadoras Andrade e Piccinini (2017, p. 11) se debruçaram sobre a análise da segunda versão da BNCC, e constataram sua perda de espaço como tema integrador e uma nítida "[...] supressão do debate socioambiental crítico, o que dificultará ainda mais sua inserção nos currículos escolares [...] " com interface com a EA.

$\mathrm{Na}$ versão definitiva algo interessante de relatar inicialmente é a forma pontual como a EA é citada na BNCC. Ela aparece uma única vez, na Introdução do documento, na página 19, especificando a relação da BNCC com o currículo e cita a Política Nacional de Educação Ambiental (lei no 9.795, de 27 de abril de 1999). Nesse contexto, a EA é reduzida a tema que deve ser incorporado ao currículo e às propostas pedagógicas.

Vale salientar que na BNCC é preconizado que os temas "são contemplados em habilidades dos componentes curriculares, cabendo aos sistemas de ensino e escolas, de acordo com suas especificidades, tratá-los de forma contextualizada" (BRASIL, 2017, p. 20). Não ficam explícitos que temas são esses em EA.

É dessa forma que aparece a EA, e depois, ao longo do texto, desaparece por completo. A mera citação da lei, parecer ou resolução não fornece elementos sobre a forma como a EA será articulada nos currículos. A EA não foi excluída da BNCC como aconteceu com as abordagens sobre gênero e sexualidade, mas, por outro lado, foi apenas citada, o que a nosso ver não garante o seu tratamento nos currículos escolares.

No que tange à abordagem técnica, essa subcategoria se configurou na fala da educação que, entre outras coisas, salienta a perda que esse tipo de abordagem caracteriza. Assim a transcrição a seguir retrata tal fala: "perde-se todo o debate crucial que há na educação ambiental, e vai para o debate técnico. Como se a questão ambiental fosse uma questão técnica." [Educação].

A abordagem técnica se estende a práticas ambientais sustentadas em aparatos tecnológicas e discursos acríticos, sem se atentar para o tratamento dos aspectos sociais, culturais, éticos... na solução ou debate das questões de caráter socioambiental. Esse tipo de abordagem se coaduna com o que é descrito como tendência pragmática (LAYRARGUES; LIMA, 2014).

As abordagens conservacionista e pragmática foram as mais citadas nas falas dos demais entrevistados que destacam o caráter a-histórico e a falta de fundamentação crítica. Seguem as falas transcritas de Coragem, Liberdade, Resistência e Revolução. "A BNCC caminha no sentido muito a-histórico da educação ambiental, que é essa perspectiva mais conservacionista e pragmática do que crítica." [Coragem]. "Até onde sei, não é contemplada, com apenas uma rápida citação a favor de práticas conservadoras/pragmáticas." [Liberdade].

Na parte introdutória e nas competências gerais da BNCC, toca-se, de forma geral, em algumas partes da educação ambiental, mas, como ocorre em todo o documento, com aquelas palavras que todo mundo gosta de ler, mas que têm um sentido muito frágil, como cidadania, sustentabilidade... Utilizam essas palavras, mas não tratam do que necessariamente se fará com tais abordagens. Nas habilidades, não está contemplada uma visão mais crítica desses termos e assim apresenta uma visão mais ligada a uma educação pragmática e conservacionista. [Resistência]. 
A educação ambiental aparece como tema, e as leis e pareceres que são políticas públicas aparecem pretensamente para legitimar a BNCC no que se refere ao tratamento da educação ambiental. Porém, se esvazia ainda mais a educação ambiental, pois ela nem é vista como um conjunto de temas. A educação ambiental, de forma imprecisa, conservadora e limitada, vista como temas [água...], trabalha de forma fragmentada. [Revolução].

Na concepção de tais entrevistados, a EA, na BNCC, quando aparece em forma de tema, vem consolidar o esvaziamento ou completa ausência de uma abordagem crítica, para o favorecimento de temas relacionado à preservação e conservação da natureza, como ideias sobre sustentabilidade vinculadas ao desenvolvimento e mudança comportamental, sem repensar ou transformar a forma como o modelo capitalista explora a natureza.

A abordagem crítica, por sua vez, na visão dos entrevistados, potencializa o repensar a relação sociedade-ser humano-natureza e se coloca a questionar as relações de classes fundamentais em: desigualdade social e cultural, desigualdade de distribuição de terras, injustiça socioambiental, ataques a direitos humanos das minorias (pobre, negro, mulheres. índio, quilombola, sem terra, sem teto, LGBT).

Nessa perspectiva, questionamos: qual o interesse de uma política pública de ordem curricular ao silenciar abordagens críticas em EA? Um documento oficial, que parte de uma política pública educacional no âmbito curricular, que silencia problemas socioambientais marcados por jogos de interesses, pela desigualdade social, por conflitos territoriais, má distribuição de renda e terras..., que geram injustiças a ponto de afetar direitos humanos e destruir o ambiente como um todo, tem a ideologia de aprofundar a desigualdade socioambiental para o favorecimento de grupos hegemônicos que estão no topo da pirâmide social a oprimir a maior parte da sociedade brasileira, que é o povo que sustenta a base de tal pirâmide.

Fica evidenciado, portanto, que em um documento oficial, voltado para os interesses neoliberais do sistema capitalista, não se tem interesse em abordar a EA com mais concretude e com elementos que garantam a sua compreensão como um campo de conhecimento consolidado.

\section{Considerações Finais}

As vozes dos entrevistados se coadunam com a literatura aqui apresentada sobre as críticas formuladas à BNCC, no que tange a currículo mínimo, redução de conteúdos críticos, precarização e privatização da educação, e a formação instrumental voltada para o mercado de trabalho, secundarizando uma formação cidadã.

No âmbito da EA, a questão do tratamento da questão ambiental de modo instrumentalizado e dissociado das questões sociais, e a ausência de abordagens críticas também foram salientadas, o que reforça o argumento de que o documento legitima e fortalece uma formação que negligencia os problemas socioambientais e desqualifica a formação de pessoas atuantes em prol de justiça e igualdade socioambientais.

Os dados também revelam a necessidade de apropriação, de debate e mais reflexões sobre o documento pelos atores sociais do 'chão da escola' e comunidades científicas para que se possa lutar pelo resgate dos conhecimentos críticos e pelo combate à formação voltada para o trabalho produtivo e alienado aos filhos das classes populares (FRIGOTTO, 2005). 


\section{Agradecimentos}

Agradecemos ao Conselho Nacional de Desenvolvimento Científico e Tecnológico (CNPq) pela bolsa de pós-doutoramento concedida à primeira autora desse artigo.

\section{Referências}

ADRIÃO, T.; PERONI, V. A formação das novas gerações como um campo de os negócios. In: AGUIAR, M. A.; DOURADO, L. F. (org.). A BNCC na contramão do PNE 2014-2024: avaliação e perspectivas. Recife: ANPAE, 2018. p. 49-54.

AGUIAR, M. A. S. Relato da resistência à instituição da BNCC pelo Conselho Nacional de Educação mediante pedido de vista e declarações de voto. In: AGUIAR, M. A.; DOURADO, L. F. (org.). A BNCC na contramão do PNE 2014-2024: avaliação e perspectivas. Recife: ANPAE, 2018. p. 8-22.

ANDRADE, M. C. P.; PICCININI, C. L. Educação ambiental na base nacional comum curricular: retrocessos e contradições e o apagamento do debate socioambiental. In: ENCONTRO PESQUISA EM EDUCAÇÃO AMBIENTAL, 9., 2017, Juiz de Fora. Anais [...]. Juiz de Fora: UFJF, 2017.

BARROSO, J. Estado, a educação e regulação das políticas públicas. Educação e Sociedade, Campinas, v. 26, n. 92, p. 725-751, 2005. Disponível em: http://www.scielo.br/pdf/es/v26n92/v26n92a02.pdf. Acesso em: 25 mar. 2020.

BOGDAN, R.; BIKLEN, S. Investigação qualitativa em educação: uma introdução à teoria e aos métodos. Porto: Porto Editora, 1994.

BRASIL. Ministério da Educação. Base nacional comum curricular: educação é a base. Brasília: MEC, 2017.

BRASIL. Ministério da Educação. Base nacional comum curricular: versão preliminar segunda versão. Brasília: MEC, 2016. Disponível em: http://basenacionalcomum.mec.gov.br/images/relatoriosanaliticos/bncc-2versao.revista.pdf. Acesso em: 25 mar. 2020.

BRASILEIRO, T. S. A.; VALENGA, C. T.; COLARES, M. L. I. Currículo e políticas públicas: reflexões pertinentes aos processos contemporâneos de formação e prática docente no contexto da interdisciplinaridade. Espaço do Currículo, João Pessoa, v. 3, n. 1, p. 324-336, 2010.

FRIGOTTO, G. Escola pública brasileira na atualidade: lições da história. In: LOMBARDI, J. C.; SAVIANI, D.; NASCIMENTO, M. I. M. (org.). A escola pública no Brasil: história e historiografia. Campinas: Autores Associados, 2005. p. 221-254.

LAYRARGUES, P. P.; LIMA, G. F. C. As macrotendências político-pedagógicas da educação ambiental brasileira. Ambiente \& Sociedade, São Paulo, v. 17, n. 1, p. 23-40, 2014. Disponível em: http://www. scielo.br/pdf/asoc/v17n1/v17n1a03.pdf. Acesso em: 25 mar. 2020.

LEHER, R. A sociedade civil contra a esfera pública. Revista de Políticas Públicas, São Luís, v. 9, n. 1, p. 129-156, 2005. Disponível em: http://www.periodicoseletronicos.ufma.br/index.php/rppublica/ article/view/3771. Acesso em: 25 mar. 2020.

LEHER, R. Reforma do estado: o privado contra o público. Trabalho, Educação e Saúde, Rio de Janeiro, v. 1, n. 2, p. 27-51, 2003. DOI: https://doi.org/10.1590/S1981-77462003000200003 
LOPES, A. C. Apostando na produção contextual do currículo. In: AGUIAR, M. A.; DOURADO, L. F. (org.). A BNCC na contramão do PNE 2014-2024: avaliação e perspectivas. Recife: ANPAE, 2018. p. 2327.

LOPES, A. C.; MACEDO, E. O pensamento curricular no Brasil. In: LOPES, A. C.; MACEDO, E. (org.). Currículo: debates contemporâneos. São Paulo: Cortez, 2002. p. 13-54.

LOUREIRO, C. F. B. Teoria social e questão ambiental: pressupostos para uma práxis crítica em educação ambiental. In: LOUREIRO, C. F. B.; LAYRARGUES, P. P.; CASTRO, R. S. (org.). Sociedade e meio ambiente: a educação ambiental em debate. São Paulo: Cortez, 2002. p. 13-52.

MACEDO, E. "A base é a base": e o currículo o que é? In: AGUIAR, M. A.; DOURADO, L. F. (org.). A BNCC na contramão do PNE 2014-2024: avaliação e perspectivas. Recife: ANPAE, 2018. p. 28-33.

MACEDO, E. Base nacional curricular comum: a falsa oposição entre conhecimento para fazer algo e conhecimento em si. Educação em Revista, Belo Horizonte, v. 2, n. 2, p. 45-67, 2016. DOI: https://doi. org/10.1590/0102-4698153052

MAZZEU, L. T. B. A pedagogia histórico-crítica como expressão teórica do marxismo na educação e a crítica à formação por competências. Revista de Educação, Campinas, n. 23, p. 45-53, 2007.

MORAES, R.; GALIAZZI, M. C. Análise textual discursiva. 2. ed. rev. Ijui: Ed. Unijuí, 2011.

ROCHA; N. F. E.; PEREIRA, M. Z. C. O que dizem sobre a BNCC: produções sobre a BNCC no período de 2010 a 2015. Espaço do Currículo, João Pessoa, n. 2, v. 9, p. 215-236, 2016.

SANTINELO, P. C. C.; ROYER, M. R.; ZANATTA, S. C. A Educação ambiental no contexto preliminar da base nacional comum curricular. Pedagogia em Foco, Iturama, v. 11, n. 6, p. 104-115, 2016.

SAVIANI, D. Escola e democracia. Campinas: Autores Associados, 2018.

SILVA, S. N.; EL-HANI, C. N. A abordagem do tema ambiente e a formação do cidadão socioambientalmente responsável. Revista Brasileira de Pesquisa em Educação em Ciências, Belo Horizonte, v. 14, n. 2, p. 225-234, 2014. Disponível em: https://periodicos.ufmg.br/index.php/rbpec/ article/view/4363. Acesso em: 25 mar. 2020.

SOUZA, C. Políticas públicas: uma revisão da literatura. Sociologia, Porto Alegre, n. 16, p. 20-45, 2006.

STANKEVECZ, P. F.; CASTILLO, N. I. A construção da base nacional comum curricular na mídia: que atores e posições foram veiculados pelo jornal Folha de São Paulo. Horizontes, Itatiba, v. 36, n. 1, p. 31-48, 2018.

VEIGA, J. M. Base nacional comum curricular (BNCC) foi tema de debate entre associações científicas em colóquio promovido pela ANPED: novo documento será entregue ao CNE esta semana pelo MEC. Anped: Rio de Janeiro, 27 abr. 2016. Disponível em: http://www.anped.org.br/news/base-nacionalcomum-curricular-bncc-foi-tema-de-debate-entre-associacoes-cientificas-em. Acesso em: 30 jun. 2017.

VENCO, S. B.; CARNEIRO, R. F. Para quem vai trabalhar na feira... essa educação está boa demais": a política educacional na sustentação da divisão de classes. Horizontes, Itatiba, v. 36, n. 1, p. 7-15, 2018.

WUTZKI, N. C.; TONSO, S. A educação ambiental e a $2^{\text {a }}$ versão preliminar da base nacional curricular comum (BNCC): uma reflexão sobre a área de ciências da natureza. In: ENCONTRO NACIONAL DE PESQUISA EM EDUCAÇÃO EM CIÊNCIAS, 11., 2017, Florianópolis. Anais [...]. Florianópolis: UFSC, 2017. p. 1-9. 